\title{
Hypopharyngeal Cancer pN1 TNM Finding v6 and v7
}

National Cancer Institute

\section{Source}

National Cancer Institute. Hypopharyngeal Cancer pN1 TNM Finding v6 and v7. NCI

Thesaurus. Code C64584.

Hypopharyngeal cancer with metastasis to a single ipsilateral lymph node, $3 \mathrm{~cm}$ or less in greatest dimension. (from AJCC 6th and 7th Eds.) 